\title{
Charles Ess-Commentary on The Onlife Manifesto
}

\author{
Charles Ess
}

$\S 1.1$. I review many of these challenges and recently developed alternatives - including phenomenology, virtue ethics, the role of embodiment in our knowing and navigating the world, and relational selfhood - in my chapter in this volume.

$\S 1.3$. As a result, ethics was a matter of rational and disembodied autonomous subjects, rather than a matter of social beings.

To expand on this slightly: ethics in Western modernity has thereby been dominated by traditions of deontology (affiliated with Kant and predominant in Germanic countries); utilitarianism (beginning with Bentham and Mill, and predominant in English-speaking countries), and French moralism (represented by Montaigne and Ricoeur: Stahl 2004, p. 17).

As discussed in my chapter, the shift towards more relational understandings of selfhood (highlighted in $\S 4.2$ - see also below) further entails a shift towards virtue ethics. See further: Ess (2013), pp. 238-243, along with sample applications of virtue ethics to digital media (pp. 243-245) and "Emerging notions of relational selfhood and distributed morality" (pp. 259-263).

$\S 3.6 . .$. the [public/private] distinction when expressed in spatial and dualistic terms. The Internet is an important extension of the public space, even when operated and owned by private actors. The notions of fragmented publics, of third spaces, and of commons, and the increased focus on use at the expense of ownership all challenge our current understanding of the public-private distinction. (Emphasis added, CE)

For additional details on how "privacy" is reconceptualized in light of these transformations (most centrally, the shift from more individual towards more relational conceptions of selfhood) - including, most importantly, Helen Nissenbaum's theory of privacy as "contextual integrity" (2010) — see my contribution to this volume, and Ess and Fossheim (2013).

The text I have highlighted points towards an increasingly urgent area of analysis and debate - namely, new opportunities and risks to democratic processes,

C. Ess $(\square)$

Department of Media and Communication, University of Oslo, Oslo, Norway

e-mail: c.m.ess@media.uio.no 
norms, and rights, beginning with freedom of expression, as taken up in our Onlife public spheres, where these public spheres are increasingly controlled by corporations. These risks include "corporate censorship"-i.e., limitations on online expression as imposed by, e.g., Apple, Facebook, Google, and other major owners of what are increasingly our default public spaces. This censorship is both aesthetic-e.g., Facebook and Apple's allergies to women's breasts (perceived as U.S.centric prudishness in much of the rest of the world) and political (e.g., Hestres 2013). Moreover, as recent revelations of the U.S. National Security Agency's PRISM program dramatically highlight, these and other corporations rarely resist governmental requests for the massive amount of "our" data that they hold and process.

$\S 4.2$ Relational self. Shaping policies in the remit of the Onlife experience means resisting the assumption of a rational disembodied self, and instead stabilising a political conception of the self as an inherently relational free self.

Again, the embodied and relational self is a core focus of my contribution to this volume. Most recently, Elaine Yuan (2013) has developed what to my knowledge is the most extensive and nuanced critique of what she calls a "culturalist" approach to Internet Studies - i.e., the radically interdisciplinary and cross-cultural field of inquiry into our lives Onlife - where such a "culturalist" approach rests precisely on the high modern assumption of a radically autonomous individual moral agent. Yuan examines East Asian societies, including China, as thereby exemplifying the concrete realities of relational selfhood - specifically as shaped by Confucian tradition - as contemporary alternatives. Yuan's analysis and findings importantly corroborate and extend my discussion of the relational self and Confucian societies in the 4th section of my contribution to this volume.

$\S$ 4.3. Digitally literate society: Endorsing responsibility in a hyperconnected reality requires acknowledging how our actions, perceptions, intentions, morality, even corporality are interwoven with technologies in general, and ICTs in particular. (Emphasis added, CE)

As I seek to argue in my contribution, we should be careful not to be mislead by the term "digital" in the phrase "digitally literate society." Rather, as phenomenology and neuroscience articulate, we remain embodied and thereby analogue creatures in ways that are importantly distinctive from "the digital". In particular, I urge that our attention to "digital literacies"-what in Medium Theory is articulated in terms of the secondary orality of "electric media," including our digital/media environments - be balanced by continuing attention to the skills and abilities affiliated with literacy-print, beginning with writing as a "technology of the self," meaning the individual-autonomous self required for robust democratic societies.

Open Access This chapter is distributed under the terms of the Creative Commons Attribution Noncommercial License, which permits any noncommercial use, distribution, and reproduction in any medium, provided the original author(s) and source are credited. 


\section{References}

Ess, Charles. 2013. Digital media ethics. 2nd ed. Cambridge: Polity Press.

Ess, Charles, and Hallvard Fossheim. 2013. Personal data: Changing selves, changing privacies. In The digital enlightenment yearbook 2013: The value of personal data, eds. Mireille Hildebrandt, Kieron O'Hara, and Michael Waidner, 40-55. Amsterdam: IOS Amsterdam.

Hestres, Luis. E. 2013. App neutrality: Apple's app store and freedom of expression online. International Journal of Communication 7: 1265-1280.

Nissenbaum, Helen. 2010. Privacy in context: technology, policy, and the integrity of social life. Palo Alto: Stanford University Press.

Stahl, Bernd Carsten. 2004. Responsible management of information systems. Hershey: Idea Group.

Yuan, Elaine J. 2013. A culturalist critique of 'online community' in new media studies. New Media \& Society 15 (5): 665-679. 